\title{
Change of Genotoxicity of Simulated Textile Dyeing Wastewater during Anoxic-aerobic Treatment
}

\author{
H. JIANG, X.H. XIE*, N. LIU, F. YANG, L.Y. ZHU, J.S LIU* \\ College of Environmental Science and Engineering, Donghua University, Shanghai, China \\ State Environmental Protection Engineering Center for Pollution Treatment and Control in Textile Industry, \\ Donghua University, Shanghai, China.
}

\begin{abstract}
The pollution of textile dyeing wastewater is of highly concern for its notorious biotoxicity, especially the genotoxicity, which can cause DNA damage and chromosome aberration to aquatic flora and fauna. In this study, a lab-scale reactor system was constructed to study the change of genotoxicity during the anoxic-aerobic treatment of simulated textile dyeing wastewater. The genotoxicity of wastewater samples were evaluated by SOS/umu test. The results revealed that the genotoxicity significantly increased by anoxic treatment, and could not be completely eliminated after aerobic treatment. By fractionating dissolved organic matters $(\mathrm{DOM})$ in wastewater into different fractions, it was found that hydrophobic acids (HOA) and the hydrophobic neutrals (HON) were the key fraction with genotoxic activity. By comparing the genotoxic equivalent of the samples and their corresponding dissolved organic carbon (DOC) value, it was found that the aerobic effluent had higher genotoxic intensity than original influent based on DOC.
\end{abstract}

KEYWORD: Simulated Textile Dyeing Waster; Genotoxicity; Anoxic-aerobic Treatment; Dissolved Organic Matters

\section{INTRODUCTIONS}

Because of the prosperity of the textile and dyeing industry, thousands of dye stuffs are synthesized and discharge into the environment in the form of effluents daily. In addition to the aesthetic problem, the textile dyeing wastewater is genotoxic and mutagenic to the aquatic flora and fauna, which consequently can be a grave pollution problem of ecosystem and public healthy (Ohe et al., 2004). Many researchers have reported that the surface water elicited mutagenic activity near the textile and dyeing industrial complex, and even the underground water was affected (Kwon et al., 2008; Mathur et al., 2005).

To comply with discharge permit limits, biological technique is widely used in the treatment of textile wastewater for its high efficiency and low-cost. But some trace organic contaminant such as genotoxic chemicals in textile effluent cannot be completely eliminated during biological treatment (Bertanza et al., 2013). In order to achieve the decolorization and detoxification of textile dyeing effluent, many researchers concentrated on the isolation of specific strain and mixed strains to degrade the target dyes (Jadhav et al., 2011; Phugare et al., 2011). But these functional strains still have limitation in actual application.
Previous assessment of the genotoxicity is mainly focused on original influent and final effluent in textile wastewater treatment. However, related research concerning the change of genotoxicity during whole biological treatment is limited. Furthermore, many types of DOM in biologically treated wastewater, including biological soluble products and genotoxic substances, can act as the major reactant in and product of biogeochemical processes, which is worthy of attention (Wang et al., 2007). Therefore, the aim of this study was to evaluate the change of genotoxicity of simulated textile dyeing wastewater during anoxic-aerobic treatment and also investigate the nature of the genotoxic substances by combining the in vitro SOS/umu test and physicochemical analysis.

\section{MATERIALS AND METHODS}

\subsection{Lab-scale Reactor System and Simulation of Textile Dyeing Wastewater}

In order to simulate the treatment process of textile dyeing wastewater, a sequential anoxic-aerobic reactor system was constructed. Each reactor was followed by a sedimentation basin. The effective volume of anoxic, aerobic reactor and sedimentation basin were $16 \mathrm{~L}, 12 \mathrm{~L}$ and $8 \mathrm{~L}$, respectively. The 
composition of simulated dyeing wastewater was presented in Table 1. The concentration of dyes mixture was $10 \mathrm{mg} / \mathrm{L}$ of Direct Red 28, Direct Yellow 12, Reactive Black 5, Reactive blue 21 and Reactive Blue 19, thus the total concentration of dyes was $50 \mathrm{mg} / \mathrm{L}$. The starch and inorganic salts were used for providing energy, carbon source, nitrogen source and other mineral substances.

Table 1. Composition of simulated textile dyeing wastewater.

\begin{tabular}{|l|c|c|c|}
\hline Dyes & $\begin{array}{c}\text { Concentration } \\
(\mathrm{mg} / \mathrm{L})\end{array}$ & $\begin{array}{c}\text { Nutrient } \\
\text { substances }\end{array}$ & $\begin{array}{c}\text { Concentration } \\
(\mathrm{mg} / \mathrm{L})\end{array}$ \\
\hline Direct Red 28 & 10 & Starch & 1000 \\
\hline Direct Yellow 12 & 10 & $\mathrm{NH}_{4} \mathrm{Cl}$ & 85 \\
\hline Reactive Black 5 & 10 & $\mathrm{KH}_{2} \mathrm{PO}_{4}$ & 20 \\
\hline Reactive Blue 21 & 10 & $\mathrm{Na}_{2} \mathrm{SO}_{4}$ & 50 \\
\hline Reactive Blue 19 & 10 & $\mathrm{NaHCO}_{3}$ & 60 \\
\hline
\end{tabular}

\subsection{Sample Collection and Water Quality Analysis}

The operation time of reactor was over 180 day and the steady-state condition was defined by $\mathrm{COD}_{\mathrm{Cr}}$ within 5\% variation for one week in each reactor. The sample influent (named IN) was collected from feeding tank. The sample anoxic effluent (named AN) and sample aerobic effluent (named AE) were collected from their corresponding sedimentation basins. After collection, all samples were filtered through $0.45 \mu \mathrm{m}$ membrane to remove the residue, and then stored in $4{ }^{\circ} \mathrm{C}$. Characteristics of these three samples were listed in Table 2, including $\mathrm{pH}$ value, $\mathrm{COD}_{\mathrm{Cr}}, \mathrm{BOD}_{5}$, dissolved organic carbon (DOC) and decolorization rate.

Table 2 Characteristics of wastewater samples used in this study.

\begin{tabular}{|c|c|c|c|c|c|}
\hline Samples & $\mathrm{pH}$ & $\begin{array}{c}\mathrm{COD}_{\mathrm{Cr}} \\
(\mathrm{mg} / \mathrm{L})\end{array}$ & $\begin{array}{c}\mathrm{BOD}_{5} \\
(\mathrm{mg} / \mathrm{L})\end{array}$ & $\begin{array}{c}\text { DOC } \\
(\mathrm{mg} / \mathrm{L})\end{array}$ & $\begin{array}{c}\text { Decolorization rate } \\
(\%)\end{array}$ \\
\hline $\mathrm{IN}$ & 6.97 & 976 & 479 & 356 & \\
\hline $\mathrm{AN}$ & 4.73 & 395 & 287 & 139 & 67 \\
\hline $\mathrm{AE}$ & 7.21 & 182 & 48 & 74 & 72 \\
\hline
\end{tabular}

\subsection{Fractionation}

The fractionation was conducted as described by (Huang et al., 1997). The DOM in wastewater was isolated into hydrophobic acids (HOA), hydrophobic bases (HOB), hydrophobic neutrals (HON) and hydrophilic substances (HIS) by XAD-8 resin. To avoid the problem of losses upon concentration or isolation, the TOC of each fraction was determined by the quantitative method described as (Wei et al., 2008)

\subsection{Genotoxicity assay}

The Salmonella typhimurium TA1535/pSK1002 for SOS/umu test was donated from School of
Environment, Tsinghua University (Beijing, China). The genotoxicity of all samples was evaluated without S9 activation according to ISO 13829. In this assay, the 4-nitroquinoline- $N$-oxide (4-NQO) was used as positive control. The genotoxicity of all samples was characterized as equivalent 4-NQO concentration.

\section{RESULTS AND DISCUSSION}

\subsection{Change of total genotoxicity during anoxic-aerobic treatment of simulated textile wastewater}

The genotoxicity of sample IN, AN and AE was 1.32, 2.71 and $1.23 \mu \mathrm{g}-4-\mathrm{NQO} / \mathrm{L}$, respectively (Fig. 1). After anoxic treatment, the genotoxicity of the wastewater increased up to twice as much as the sample IN $(\mathrm{p}<0.05)$. Although the COD removal and decolorization rates were $81 \%$ and $72 \%$, respectively, the genotoxicity of wastewater was just slightly reduced after whole anoxic-aerobic treatment. The genotoxicity of sample AE was still more than $90 \%$ of sample IN. Since reactive textile dyes can be degraded to genotoxic compounds such as aromatic amine under anaerobic condition (Gottlieb et al., 2003), it is possible for some genotoxic compounds generated during anoxic treatment which cannot be totally eliminated under aerobic condition.

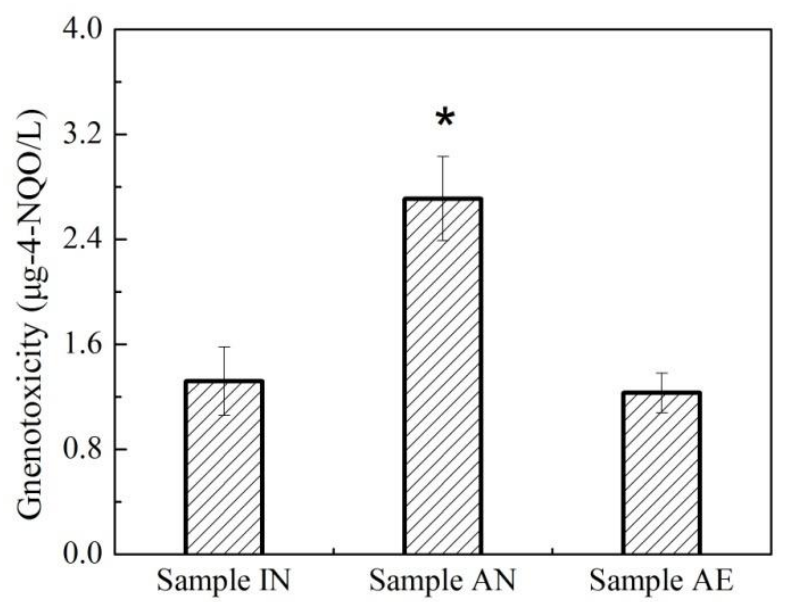

Figure 1. Change of genotoxicity of simulated wastewater during anoxic-aerobic treatment. Asterisk sign indicates that the genotoxicity of the sample was significantly different from that of the sample IN $(p<0.05)$. Error bars represent the standard deviation based on triplicate analyses.

\subsection{The genotoxicity of the different DOM fractions}

In order to study the nature and source of the genotoxicity compounds, Sample AN and AE were fractionated into four fractions $(\mathrm{HOA}, \mathrm{HON}, \mathrm{HOB}$, HIS). The resulting genotoxicity of the fractions was evaluated and shown in Figure 2. It could be seen that HOB and HIS in both samples did not exhibit 
any genotoxicity. The HOA elicited highest genotoxic activity $(1.93 \mu \mathrm{g}-4-\mathrm{NQO} / \mathrm{L})$ in all fractions of sample AN, accounting for $67 \%$ of the total genotoxicity, and the genotoxicity of HON was in the second, accounting for 33\%. Meanwhile, in sample AE, the genotoxicity of HOA and HON was $41 \%$ and $59 \%$ of total genotoxicity, respectively. Notably, The genotoxicity of HOA was drastically removed about $70 \%$ during aerobic treatment, while the genotoxicity of HON in sample AE was only lower than $10 \%$ of that in sample AN, which showed the strong resistance to elimination by aerobic reaction. These phenomena suggested that HOA and HON played as key role in change of genotoxicity during anoxic-aerobic treatment.

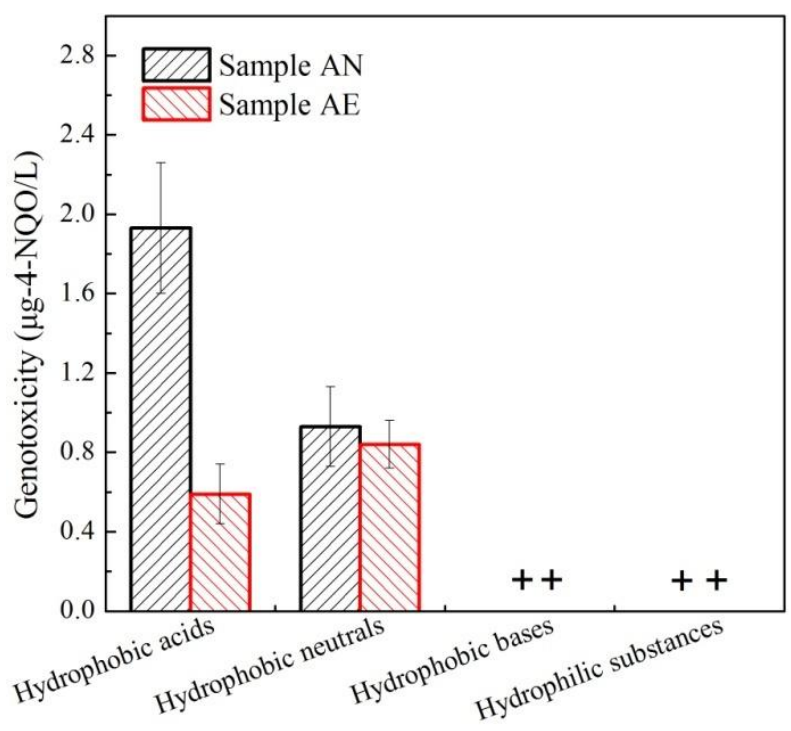

Figure 2. Changes of genotoxicity of fractions of sample AN and AE. Plus signs indicated that fractions did not exhibit genotoxicity at 200-fold. Error bars represent the standard deviation based on triplicate analyses.

\subsection{The genotoxic intensity of wastewater samples and their fractions based on TOC}

To better analyze the changes of genotoxicity during anoxic-aerobic treatment, the genotoxic equivalent of samples were compared with their corresponding DOC value to obtain the ratio of 4-NQO equivalent and DOC value, which was regarded as the unit of genotoxic intensity based on DOC. The DOC parameter of each fraction was shown in Table 3 . From Figure 3, it could be seen that the genotoxic intensity of sample IN, $\mathrm{AN}$ and $\mathrm{AE}$ was $3.7 \times 10^{-3}$, $19.5 \times 10^{-3}$ and $16.6 \times 10^{-3} \mu \mathrm{g}-4-\mathrm{NQO} / \mathrm{mg}$, respectively. The genotoxic intensity of sample AN and AE was significantly more than that of sample IN $(p<0.05)$. It also could be seen that the genotoxic intensity of HOA decreased from $74.2 \times 10^{-3}$ to $32.8 \times 10^{-3}$ $\mu \mathrm{g}-4-\mathrm{NQO} / \mathrm{mg}$ meanwhile that of HON increased from $48.9 \times 10^{-3}$ to $64.6 \times 10^{-3} \mu \mathrm{g}-4-\mathrm{NQO} / \mathrm{mg}$ after anoxic-aerobic treatment.
Table 3. DOC value of the fractions of sample AN and AE.

\begin{tabular}{|c|c|c|c|}
\hline Sample AN & DOC $(\mathrm{mg} / \mathrm{L})$ & Sample AE & DOC $(\mathrm{mg} / \mathrm{L})$ \\
\hline HOA & 26 & HOA & 18 \\
\hline HOB & 29 & HOB & 15 \\
\hline HON & 19 & HON & 13 \\
\hline HIS & 65 & HIS & 28 \\
\hline
\end{tabular}

Although the genotoxicity of simulated textile dyeing wastewater was slightly removed after anoxic-aerobic treatment, the genotoxic intensity of final effluent increased 4 times as much as the original influent. Hence, it is possible that some compounds formed during anoxic-aerobic treatment may have higher genotoxic activity.

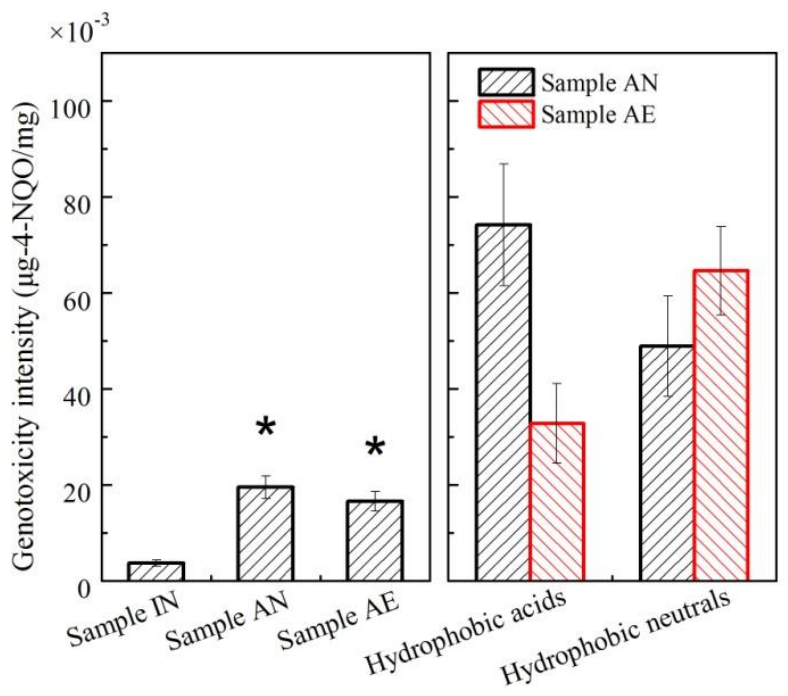

Figure 3. The genotoxic intensity of samples and fractions based on TOC. The Asterisk sign indicated that the genotoxic intensity of the sample was significantly from that of sample IN ( $p<0.05)$. Error bars represent the standard deviation based on triplicate analyses.

\section{CONCLUSION}

From the results of SOS/umu test, it was found that the genotoxicity of simulated textile dyeing wastewater increased significantly during anoxic treatment, and then decreased after aerobic reaction. Although the removal of organic matters and decolorization were of high efficiency, the elimination of genotoxicity was less than $10 \%$. By fractionation of DOM in wastewater, it was found that the HOA and HON were the key fraction with genotoxicity. By comparing the genotoxic equivalent of samples and their corresponding DOC, it was possible that some compounds with higher genotoxicity may generate during anoxic-aerobic treatment. Therefore, in addition to the toxicity of the dye itself, the effect of biologically treatment on the genotoxicity of textile dyeing wastewater should be of highly concern. 


\section{ACKNOWLEDGEMENTS}

This work was financially supported by the National Natural Science Foundation of China (21377023), Research Fund for the Doctoral Program of Higher Education of China (20100075110010, 20120075120014), Young Scientists Program of Shanghai Natural Science Fund (12ZR1440400). This work was partially supported by Shanghai Leading Academic Discipline Project (B604). Besides, we appreciated the supports from Professor $\mathrm{Hu}$ Hongying's laboratory in School of Environment, Tsinghua University (Beijing, China).

\section{REFERENCES}

[1] Bertanza, G., Papa, M., Pedrazzani, R., Repice, C., Mazzoleni, G., Steimberg, N., Feretti, D., Ceretti, E. \& Zerbini, I. 2013. EDCs, estrogenicity and genotoxicity reduction in a mixed (domestic plus textile) secondary effluent by means of ozonation: A full-scale experience. Science of the Total Environment, 458: 160-168.

[2] Gottlieb, A., Shaw, C., Smith, A., Wheatley, A. \& Forsythe, S. 2003. The toxicity of textile reactive azo dyes after hydrolysis and decolourisation. Journal of Biotechnology, 101(1): 49-56.

[3] Huang, W. J. \& Yeh, H. H. 1997. The effect of organic characteristics and bromide on disinfection by-products formation by chlorination. Journal of Environmental Science And Health Part a-Environmental Science And Engineering \& Toxic And Hazardous Substance Control, 32(8): 2311-2336.
[4] Jadhav, S. B., Phugare, S. S., Patil, P. S. \& Jadhav, J. P. 2011. Biochemical degradation pathway of textile dye Remazol red and subsequent toxicological evaluation by cytotoxicity, genotoxicity and oxidative stress studies. International Biodeterioration \& Biodegradation, 65(6): 733-743.

[5] Kwon, J. H., Lee, H. K., Kwon, J. W., Kim, K., Park, E., Kang, M. H. \& Kim, Y. H. 2008. Mutagenic activity of river water from a river near textile industrial complex in Korea. Environmental Monitoring and Assessment, 142(1-3): 289-296.

[6] Mathur, N., Bhatnagar, P., Nagar, P. \& Bijarnia, M. K. 2005. Mutagenicity assessment of effluents from textile/dye industries of Sanganer, Jaipur (India): a case study. Ecotoxicology And Environmental Safety, 61(1): 105-113.

[7] Ohe, T., Watanabe, T. \& Wakabayashi, K. 2004. Mutagens in surface waters: a review. Mutation Research-Reviews In Mutation Research, 567(2-3): 109-149.

[8] Phugare, S. S., Kalyani, D. C., Patil, A. V. \& Jadhav, J. P. 2011. Textile dye degradation by bacterial consortium and subsequent toxicological analysis of dye and dye metabolites using cytotoxicity, genotoxicity and oxidative stress studies. Journal Of Hazardous Materials, 186(1): 713-723.

[9] Wang, L. S., Hu, H. Y. \& Wang, C. 2007. Effect of ammonia nitrogen and dissolved organic matter fractions on the genotoxicity of wastewater effluent during chlorine disinfection. Environmental Science \& Technology, 41(1): 160-165.

[10] Wei, Q. S., Feng, C. H., Wang, D. S., Shi, A. Y., Zhang, L. T., Wei, Q. \& Tang, H. X. 2008. Seasonal variations of chemical and physical characteristics of dissolved organic matter and trihalomethane precursors in a reservoir: a case study. Journal Of Hazardous Materials, 150(2): 257-264. 